\title{
TLR ligand loaded exosome mediated immunotherapy of established mammary Tumor in mice
}

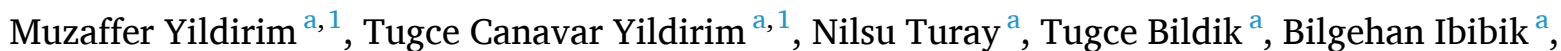 \\ Irem Evcili ${ }^{\mathrm{a}}$, Pelin Gulizar Ersan ${ }^{\mathrm{a}, \mathrm{b}}$, Unal M. Tokat ${ }^{\mathrm{a}, \mathrm{b}}$, Ozgur Sahin ${ }^{\mathrm{b}}$, Ihsan Gursel ${ }^{\mathrm{a} \text {,* }}$ \\ a Thorlab, Department of Molecular Biology and Genetics, Bilkent University, Bilkent, 06800, Ankara, Turkey \\ b Drug Discovery \& Biomedical Sciences (DDBS), College of Pharmacy, University of South Carolina, Columbia, SC 29208,Columbia
}

\section{A R T I C L E I N F O}

\section{Keywords:}

Cancer vaccine

TLR

Immune response

Breast tumor

Immunotherapy

\begin{abstract}
A B S T R A C T
Tumor-derived exosomes (TEXs) could be harnessed as an immunotherapeutic cancer vaccine. These nanovesicles are inherently possesses rich tumor antigen reservoirs. Due to their undesirable features such as poor or limited immunogenicity as well as facilitation of cancer development via mediating communication between tumor cells TEXs could be transformed into an effective immune adjuvant delivery system that initiates a strong humoral and cell-mediated tumor-specific immune response. Engineering TEXs to harbor immunostimulatory molecules still remains a challenge. Previously, we demonstrated that nucleic acid ligand encapsulated liposomes could trigger synergistic strong humoral, and cell mediated immune responses and provokes tumor regression to that of their standalone counterparts. In this study, we evaluated to immunogenicity of 4T1/Her2 cell-derived exosomes upon loading them with two potent immuno adjuvant, a TLR9 ligand, K-type CpG ODN and a TLR3 ligand, p(I:C). Engineered TEXs co-encapsulating both ligands displayed boosted immunostimulatory properties by activating antigen-specific primary and memory $\mathrm{T}$ cell responses. Furthermore, our exosome-based vaccine candidate elicited robust Th1-biased immunity as evidenced by elevated secretion of IgG2a and IFN $\gamma$. In a therapeutic cancer model, administration of4T1 tumor derived exosomes loaded with CpG ODN and p(I:C) to animals regress tumor growth in 4T1 tumor-bearing mice. Taken together this work implicated that an exosomebased therapeutic vaccine promoted strong cellular and humoral anti-tumor immunity that is sufficient to reverse established tumors. This approach offers a personalized tumor therapy strategy that could be implemented in the clinic.
\end{abstract}

\section{Introduction}

Immunotherapy has become a powerful clinical strategy to boost the activation of host immune system against tumors that evade immune surveillance and induce tolerance. These cancer therapies enhance antitumor immune responses with fewer off-target effects than traditional treatments, such as chemotherapy and radiation that lack tumor selectivity and have severe side effects [1]. Tumor antigen-based cancer immunotherapy has gained significant attention to elicit antigen-specific strong $\mathrm{T}$ and $\mathrm{B}$ cell responses, however, the purification of particular tumor antigens is challenging $[2,3]$. Therefore, identification of tumor-specific nanostructures that naturally harbors endogenous tumor antigens and further engineering these structures to co-deliver immune stimulating adjuvants yielding potent anti-tumor immunity is of great benefit during the management of established tumors. A depot system that permits simultaneous presentation of tumor antigen as well as initiating tumor-specific immune activation could offer effective tumor targeting while reducing undesirable toxicity could pave the way for patient specific anti-cancer immunotherapy [4,5].

Exosomes with a size between 30 and $150 \mathrm{~nm}$ are small extracellular vesicles secreted (any small sized EVs irrespective of their biogenesis) by all type of mammalian cells [6]. Hereafter, the term "exosomes" refers to small EVs in this work. They mediate a novel mode of intercellular communication through their bioactive cargos such as lipids, nucleic acids, metabolites, and proteins, which can be delivered to the target cells [7]. Using their natural delivery capabilities, exosomes have been successfully served as immunotherapeutic nanocarriers in cancer treatment [8]. Furthermore, they are attractive as a delivery system because

\footnotetext{
* Corresponding author.

E-mail address: ihsangursel@bilkent.edu.tr (I. Gursel).

1 Equal Contribution
} 
of their stability in circulation, biocompatibility, and low toxicity $[9,10$, $11]$.

Tumor derived exosomes (TEXs) are appropriate tumor specific antigen sources to induce immunity against tumor cells since they are capable of even presenting endogenous tumor-specific neoantigens [12]. They can transfer a wide spectrum of immunogenic tumor antigens expressed in parental tumor cells to DCs and elicit tumor-specific cytotoxic T lymphocytes $[13,14]$. As well as their modification by different methods to enrich tumor antigens, immunostimulatory molecules and microRNAs, TEXs can be loaded with therapeutic cargo [15,16]. These engineered TEXs can increase their uptake by antigen presenting cells, upregulate the expression of cancer-specific antigenic epitopes, repress immunosuppressive targets in the tumor microenvironment, improve DC maturation and enhance tumor cell elimination [17,18,19]. Moreover, Moreover, the feasibility to isolate TEXs from patients' sera enables their use in personalized immunotherapy [20]. Taken together, TEXs as a modified carrier for immunostimulatory agents along with tumor antigens can be a novel candidate for tumor vaccine.

Among immunostimulatory agents, nucleic acid-based adjuvants are safe and effective inducer of innate immune effector functions [21,22]. CpG oligonucleotides (CpG ODNs) recognized by Toll-like receptor 9 (TLR9) is one of the most extensively used adjuvants in the clinic to stimulate immune response characterized by the production of Th1 and pro-inflammatory cytokines $[23,24] \mathrm{K}$ type CpG ODN activates B cells and trigger plasmacytoid dendritic cells (pDCs) to secrete tumor necrosis factor- $\alpha$ (TNF- $\alpha$ ) [25]. Polyinosinic-polycytidylic acid (p(I:C)), a TLR3 agonist, is another potent adjuvant that has been widely studied as an anti-tumor drug in cancer patients [26]. p(I:C) is shown to induce type I and II interferons (IFN) and the activation of CD4 + and CD8 $+T$ cell responses overcoming immunosuppressive function of regulatory $\mathrm{T}$ cells in the tumor microenvironment [27, 28, 29, 30].

The simultaneous delivery of tumor cell-derived exosomes and adjuvants to the same immune cells could effectively induce a potent antitumor immune response. Herein, we co-encapsulated CpG ODN and p(I: C) into $4 \mathrm{~T} 1 / \mathrm{Her} 2$ cell-derived exosomes. These $4 \mathrm{~T} 1$ breast cancer cells were modified to overexpress Her2 tumor antigen that are present within TEXs. Our results revealed that dual adjuvant encapsulating exosome vaccine induced a strong Th1-biased Her2-specific immune response and increased the production of type II IFNs. We also demonstrated that dual adjuvant co-encapsulating exosome vaccine generated Her2-specific CD4+ memory T cell. Moreover, when used as a therapeutic vaccine, CpG ODN and $\mathrm{p}(\mathrm{I}: \mathrm{C})$ loaded exosomes significantly regressed 4T1 tumor growth in mice. Taken together, we present an exosome-based therapeutic vaccine candidate that could promote strong cellular and humoral anti-tumor immune responses that offers an effective personalized tumor therapy strategy in the clinic.

\section{Materials and methods}

\subsection{Materials}

TLR9 ligand, CpG-ODN GACGTTGACGTTGACGTTGG was purchased from Alpha DNA (Canada). TLR3 ligand, p(I:C) was from Amersham (Piscataway, NJ, USA). Her2/E75 peptide was purchased from Immunostep (Spain). All cell culture media components were from Gibco (NY, USA) and Lonza (Walkersville, MD, USA). Cytokine ELISA reagents: recombinant cytokine, monoclonal unlabeled and biotinylated antibody against $\mathrm{m}$-IFN $\gamma$ were purchased from Mabtech (Cincinnati, $\mathrm{OH}$, USA). P-nitrophenyl phosphate disodium salt substrate (PNPP) was purchased from Thermo Scientific (USA).

Immunoglobulin ELISA reagents: goat anti-mouse total IgG, IgG1, IgG2a monoclonal antibodies conjugated with alkaline phosphatase (AP) were from Southern Biotech (Birmingham, AL, USA). FACS antibodies conjugated to fluorescent chromophores were obtained from Biolegend. Rabbit monoclonal antibody against TSG101 and rabbit monoclonal antibody against Her2/ErbB2 were from Abcam
(Cambridge, UK) and Cell Signaling (Massachusetts, USA) respectively. Cytofix/Cytoperm and Perm/wash buffer were purchased from BD (New Jersey, USA).

\subsection{Mice and cell lines}

Adult Balb/c mice (female, 6-8 weeks old) were kept in the Bilkent University animal housing facility of the Department of Molecular Biology and Genetics. Mice were housed under controlled conditions at $22{ }^{\circ} \mathrm{C}$ with $12 \mathrm{~h}$ light and $12 \mathrm{~h}$ dark cycles and provided with unlimited access of food and water. All experimental procedures were approved by the animal ethical committee of Bilkent University.

4T1-luc and 4T1/Her2 cell lines were cultured in Dulbecco's Modified Eagle Medium, (DMEM) with 10\% fetal bovine serum (FBS). GFP tagged HER2 expressing mouse breast cancer cell line (4T1-HER2) was kindly provided by Prof. Michael Kershaw (Cancer Immunology Program, Peter MacCallum Cancer Center, Victoria, Australia) [41,42]. 4T1-luc cell line is originally developed by G Gary Sahagian [43].

\subsection{Isolation of tumor derived exosomes from cell culture supernatant}

Exosomes were isolated from 4T1/Her2 and 4T1-luc cell lines via differential ultracentrifugation method. Following supernatant collection from cultured cells, they were centrifuged at $1500 \mathrm{x}$ g for $10 \mathrm{~min}$ at RT to discard the cell debris. Supernatants were transferred to ultracentrifugation tubes (Beckmann Coulter) and centrifuged at 10,000 x g for $10 \mathrm{~min}$ at $+4{ }^{\circ} \mathrm{C}$ to remove any large particles, followed by a second centrifugation at $30,000 \mathrm{x} g$ for $30 \mathrm{~min}$. This generated a pellet consisting of medium sized EVs and an upper aqueous phase containing the exosomes. The supernatant was collected and passed through a $0.2 \mu \mathrm{m}$ filter to ensure removal of larger particles. To sediment exosomes, filtered supernatant was centrifuged at $100,000 \mathrm{x}$ f for $90 \mathrm{~min}$ at $+4{ }^{\circ} \mathrm{C}$. The pellet was washed once with PBS at 100,000 x g for another $90 \mathrm{~min}$ at $+4{ }^{\circ} \mathrm{C}$. Following washing, supernatants were aspirated, and the exosome pellet was resuspended in an appropriate volume of $\mathrm{Ca}^{2+}$ / $\mathrm{Mg}^{2+}$ free 1x PBS and used in further studies.

\subsection{Exosome characterization}

Forty $\mu \mathrm{L}$ of carboxyl modified latex beads (Life Technologies) were incubated with $40 \mu \mathrm{g}$ of LEAF purified anti-mouse CD81 antibody (Biolegend) at RT for $30 \mathrm{~min}$. Then, the volume was adjusted to $500 \mu \mathrm{L}$ with $1 \mathrm{x}$ PBS and bead-antibody mix was incubated overnight at RT by continuous rotation. Following incubation, beads were blocked with $5 \%$ BSA containing $1 \mathrm{x}$ PBS for $4 \mathrm{~h}$ at RT by rotation. To analyze the specific molecules on exosomes, two $\mu \mathrm{g}$ of exosomes were mixed with antimouse CD81 conjugated beads and incubated at RT overnight. Following washing by centrifugation at $13,200 \mathrm{x} \mathrm{g}$, bead-associated exosomes were incubated separately with $2 \mu \mathrm{g} / \mathrm{mL}$ anti-CD9-FITC, anti-CD81-PE antibodies in sodium azide containing FACS buffer or with their corresponding isotype controls for $30 \mathrm{~min}$ at RT. The exosome-bead complexes were washed and analyzed with Novocyte D3000 (Agilent, California, USA).

Total cellular and exosomal proteins were extracted using a RIPA lysis buffer and samples were vortexed and sonicated, respectively. Protein concentration was determined by BCA Protein Assay Reagent Kit (Thermo Scientific). Twenty five $\mu \mathrm{g}$ of cell lysate, medium sized EVs lysate or exosome lysate were separated on $10 \%$ SDS-polyacrylamide gel for $90 \mathrm{~min}$ at $120 \mathrm{~V}$ following $10 \mathrm{~min}$ run on 5\% SDS-polyacrylamide resolving gel and then were transferred to PVDF membranes (Thermo Scientific) by applying $100 \mathrm{~V}$ for $90 \mathrm{~min}$. Membranes were blocked with $5 \%$ non-fat dry milk containing $1 \mathrm{x}$ PBS-T for $2 \mathrm{~h}$ at RT. Then, blocked membranes were incubated with primary antibodies against TSG101 (Abcam) or Her2 (Cell Signaling) prepared in 5\% non-fat dry milk containing $1 \mathrm{x}$ PBS-T at a 1:1000 dilution at $+4{ }^{\circ} \mathrm{C}$ overnight. Following primary antibody incubation, membranes were washed and incubated 
A.
CD81

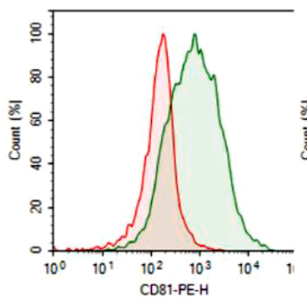

CD9

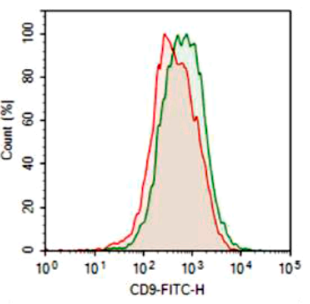

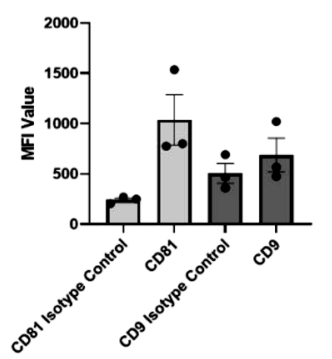

B.

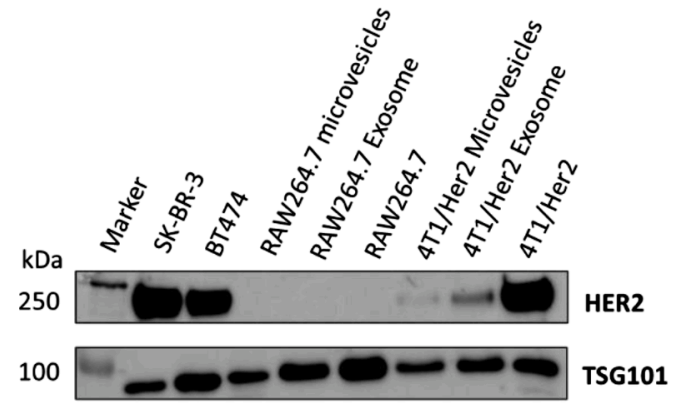

C.

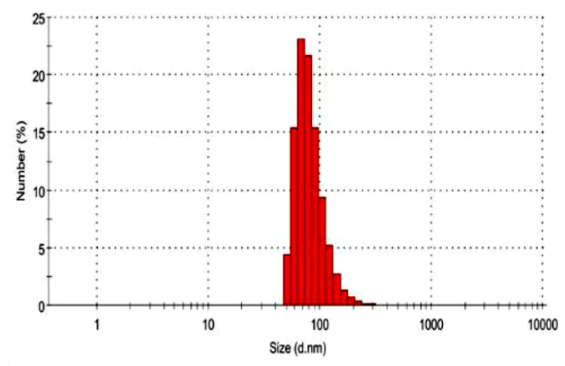

D.

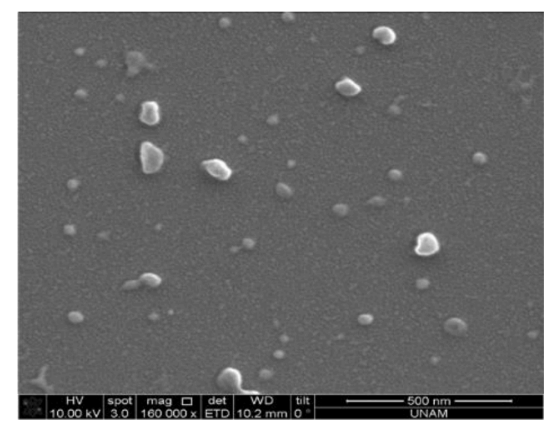

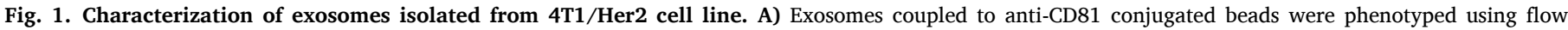

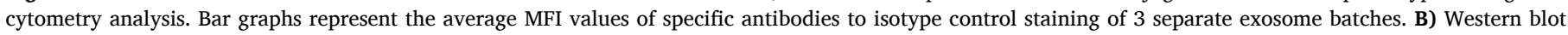

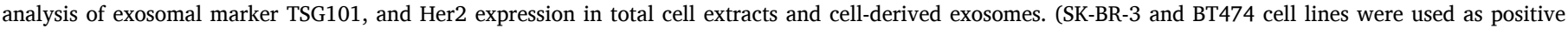

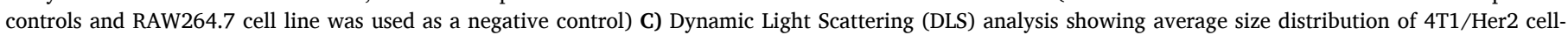

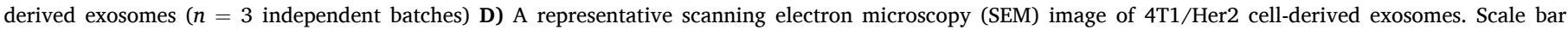
represents $500 \mathrm{~nm}$.

with 1:5000 diluted secondary antibodies, HRP conjugated horse antimouse IgG (Cell Signaling) for Tsg101 and Her2 in 5\% non-fat dry milk supplemented 1x PBS-T at RT for $1 \mathrm{~h}$ Membranes were developed using the chemiluminescent detection kit, ECL + from Amersham according to the manufacturer's protocols and visualized by Amersham Chemiluminescence Imager 600 (GE, Amersham).

To analyze the size of exosomes by dynamic light scattering (DLS) using Zetasizer Nano ZS (Malvern, UK), exosomes were diluted in PBS and triplicate readings of samples were recorded.

Purified exosomes were verified by scanning electron microscopy (SEM). Ten $\mu \mathrm{L}$ of the exosome solution were deposited on silica surfaces. After evaporation, samples were sputter-coated with $8 \mathrm{~nm}$ of $\mathrm{Au} / \mathrm{Pd}$ alloy using a precision coating system (Gatan Inc, USA).

\subsection{Loading of exosomes with $C P G O D N$ and $p(I: C)$}

Thirty $\mu$ g of exosome were mixed with $30 \mu \mathrm{g}$ CpG ODN and $30 \mu \mathrm{g}$ p: C. The mixture was snap-frozen in liquid nitrogen and lyophilized overnight in VirTis Bench Top K Freeze Dryer (SP Industries, PA, USA). The exosome-ligand powder mixture was rehydrated in a controlled fashion by addition of nuclease free $\mathrm{ddH}_{2} \mathrm{O}$. Then, this rehydrated mixture was vortexed for $15 \mathrm{~s}$ every $2 \mathrm{~min}$ for a period of $20 \mathrm{~min}$. Next, 1 $\mathrm{x} \mathrm{Ca} 2+/ \mathrm{Mg} 2+$ free PBS was added, and the mixture was incubated at RT for another $10 \mathrm{~min}$. Then, the mixture was vortexed for $15 \mathrm{~s}$ and the controlled rehydration process was completed with the addition of $1 \mathrm{x}$ $\mathrm{Ca} 2+/ \mathrm{Mg} 2+$ free PBS to adjust the desired concentration of ligand encapsulated exosome solution. As such prepared exosome formulations were maintained at $+4{ }^{\circ} \mathrm{C}$ until further use.

The encapsulation efficiency was performed from three independent batches of each exosome preparations. To detect CpG ODN loading, 30 $\mu \mathrm{g}$ Cy5-labeled CpG ODN and $30 \mu \mathrm{g}$ unlabeled pI:C were mixed with 30 $\mu \mathrm{g}$ of exosome. Following reconstitution as described above, the Cy5signal was followed both from the exosome pellet and from the unencapsulated fraction of supernatant using fluorometer. Next, $30 \mu \mathrm{g}$ unlabeled CpG ODN and $30 \mu \mathrm{g}$ FITC-labelled pI:C were mixed with $30 \mu \mathrm{g}$ of exosome, and same procedure was performed to identify the pIC loading. For each ligand the encapsulation efficiencies were found to be $88.8 \pm 9.2 \%$ for the CpG ODN and $94.1 \pm 7.3 \%$ for pIC.

\subsection{Immunization of balb/c mice and splenocyte isolation}

6-8 weeks-old female Balb/c mice (4 per group) were vaccinated 2 times in 2-week intervals intraperitoneally (I.P) with PBS, only $30 \mu \mathrm{g}$ exosome, free form of $30 \mu \mathrm{g}$ exosome $+30 \mu \mathrm{g}$ CpG ODN and $30 \mu \mathrm{g}$ (I:C) or exosome loaded with $\mathrm{CpG} \mathrm{ODN}+p(\mathrm{I}: \mathrm{C})$. Two weeks after the last booster dose, all mice were sacrificed and their splenocytes and blood serum were collected aseptically for the detection of cellular immune responses.

\subsection{In vitro stimulation}

Splenocytes $\left(2 \times 10^{6}\right.$ cell $/ \mathrm{mL}$ in $\left.250 \mu \mathrm{l}\right)$ were stimulated with $10 \mu \mathrm{g} /$ $\mathrm{mL} 4 \mathrm{~T} 1 / \mathrm{Her} 2$ cell-derived exosome for $72 \mathrm{~h}$ at $37{ }^{\circ} \mathrm{C}$ in a $5 \% \mathrm{CO}_{2}$ incubator. After stimulation, the supernatants were collected and used for IFN $\gamma$ cytokine ELISA.

\subsection{Enzyme-linked immunosorbent (ELISA) assay}

Immulon $2 \mathrm{HB}$ microtiter plates (Thermo Scientific, San Jose, CA, USA) were coated with Her2 E75 peptide $(40 \mu \mathrm{g} / \mathrm{mL}), 4 \mathrm{~T} 1 / \mathrm{Her} 2$ cell lysate $(10 \mu \mathrm{g} / \mathrm{mL}), 4 \mathrm{~T} 1 / \mathrm{Her} 2$ exosome lysate $(10 \mu \mathrm{g} / \mathrm{mL})$ and antimouse IFN $\gamma(2 \mu \mathrm{g} / \mathrm{mL})$ respectively, and then blocked with PBS-BSA. Serially diluted standards and culture supernatants or serially diluted mouse sera were added to plates for overnight at $4{ }^{\circ} \mathrm{C}$. Cytokine was detected using biotinylated anti-mouse IFN $\gamma(1 \mu \mathrm{g} / \mathrm{mL})$ antibody followed by phosphatase-streptavidin whereas bound IgG subclasses were detected using alkaline phosphatase streptavidin conjugated antimouse IgG (1:1000), anti- mouse IgG1 (1:1000) and anti-mouse IgG2a 

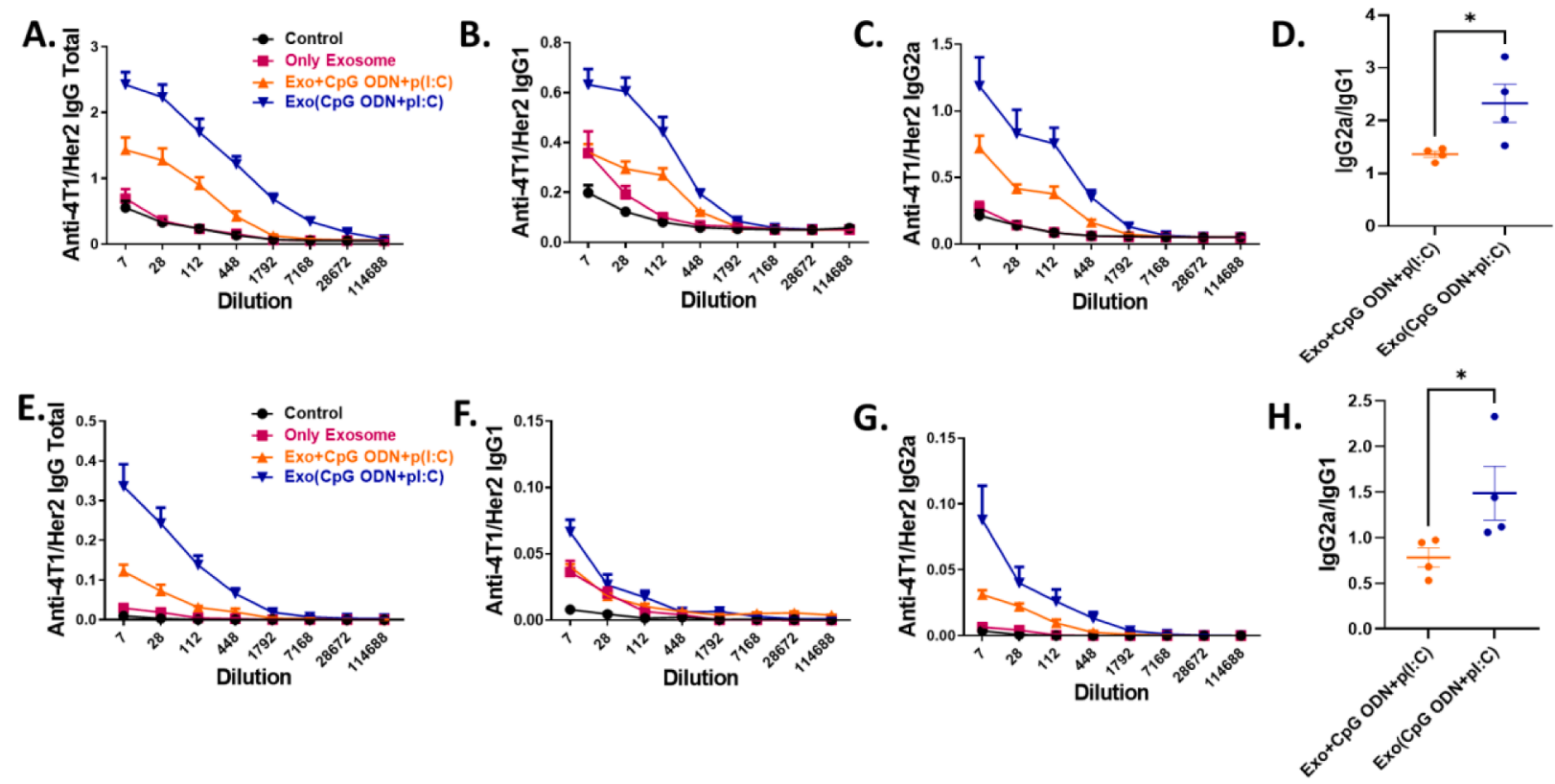

Fig. 2. 4T1/Her2 cell-derived exosomes loaded with CpG ODN and p(I:C) immunization generates sustained and magnified anti-4T1/Her2 immune responses. Mice ( $n=4$ mice/group) were injected i.p. with PBS, only $30 \mu \mathrm{g}$ exosomes, free form of $30 \mu \mathrm{g}$ exosomes $+30 \mu \mathrm{g}$ CpG ODN and $30 \mu \mathrm{g}$ p(I:C) or exo(CpG $\mathrm{ODN}+p(\mathrm{I}: \mathrm{C})$ ) on days 0 and 14. Mice were sacrificed on day 28. A-C) Sera of immunized mice were investigated for systemic anti-4T1/Her2 antibody production against 4T1/Her2 cell lysate. End-point average titers of anti-4T1/Her2 total IgG, IgG1 and IgG2a responses of mice were shown. D) IgG2a/IgG1 ratio of individual mouse either immunized with free or immunized with exosomal formulation at 2 weeks after booster injection (at 1:120 dilution against 4T1/Her2 cell Lysate). Mann-Whitney test was used for statistical analysis. E-G) Sera of immunized mice were investigated for systemic anti-4T1/Her2 antibody production against protein extracts of 4T1/Her2 cell-derived exosomes. End-point average titers of anti-4T1/Her2 total IgG, IgG1 and IgG2a responses were shown. H) IgG2a/IgG1 ratio of individual mouse either immunized with free or immunized with exosomal formulation at 2 weeks after booster injection (at 1:15 dilution against protein extracts of 4T1/Her2 cell-derived exosomes). Mann-Whitney test was used for statistical analysis. The data indicate the mean \pm SEM $(n=4)$. Statistically significant differences designated as follows: ns: $p>0.05, *: p<0.05$. Exo: exosome.

(1:1000) antibodies and developed by the addition of PNPP substrate.

\subsection{Intracellular cytokine assay via flow cytometry}

$10^{6}$ cells/mL of splenocytes in medium containing Brefeldin A ( $5 \mu \mathrm{g} /$ $\mathrm{mL}$, was included in the last $6 \mathrm{~h}$ ) was stimulated with 4T1/Her2 derived exosomes $(10 \mu \mathrm{g} / \mathrm{mL})$ for $24 \mathrm{~h}$ at $37{ }^{\circ} \mathrm{C}$. After stimulation, cells washed two times with stain buffer (2\% FCS in PBS). Cells were stained with 1 $\mu \mathrm{g} / \mathrm{mL}$ anti CD45-PE/Cy7, anti CD3-Pacific Blue, anti CD4-FITC, anti CD8-PE, anti CD44-APC/Cy7, anti CD62L-BV605 for $30 \mathrm{~min}$ at $4{ }^{\circ} \mathrm{C}$. The cells were washed with stain buffer and fixed with Cytofix/Cytoperm solution. Fixed cells were washed two times with Perm/Wash buffer and then stained with $1 \mu \mathrm{g} / \mathrm{mL}$ anti IFN $\gamma$-FITC antibody for $30 \mathrm{~min}$ at $4{ }^{\circ} \mathrm{C}$. The cells were washed with Perm/Wash buffer and suspended in $300 \mu \mathrm{L}$ stain buffer for flow cytometric analysis with Novocyte D3000 (Agilent, California, USA).

\subsection{The therapeutic model of 4T1-luc tumor mice model}

6-8 week-old female Balb/c mice were injected with $2 \times 10^{5} 4 \mathrm{~T} 1$-luc tumor cells into right mammary fat pads orthotopically with 5-6 mice per group. Tumor-bearing mice were then intraperitoneally injected with a PBS and $30 \mu \mathrm{g}$ exosome loaded with $30 \mu \mathrm{g}$ CpG ODN and $30 \mu \mathrm{g} p$ (I:C) at day $=, 1,4,7,10,17,24$ and 31 after tumor inoculation. Tumor growth was monitored by measuring the tumor volume with a caliper after tumors become palpable. Tumor volumes were calculated as length $\times$ width $^{2} / 2$.

For IVIS spectrum, Caliper Lifesciences Lumina III series was used to visualize tumor growth and each mouse received $150 \mathrm{mg}$ Luciferin $/ \mathrm{kg}$ according to the datasheet suggestion.

\subsection{Statistical analysis}

One-way ANOVA with Kruskal Wallis and Mann-Whitney tests were employed to assess the significance of differences among the groups. Survival analysis was performed using log-rank test (GraphPad Prism version 9, San Diego, California). $P<0.05$ was statistically significant.

\section{Results}

\subsection{Characterization of exosomes}

Exosomes were isolated from the 4T1/Her2 cell culture supernatants using differential ultracentrifugation method as described in Material and Methods. Isolated exosomes were subjected to analysis of i) surface marker expression by flow cytometry, ii) exosome-specific protein and Her2 expression by immunoblotting, iii) size distribution by DLS and iv) morphological analysis by SEM. Exosomes were verified by detecting the expression of positive protein markers CD81, CD9 (Fig. 1A) and TSG101 (Fig. 1B). Tumor cell-derived exosomes are a good source of cellular components that stimulate the immune response, such as tumorassociated antigens. To check whether the isolated exosome pools carry antigen, we confirmed that purified exosomes of 4T1/Her2 cells also express Her2 whereas isolated exosomes of RAW264.7 as a negative control does not (Fig. 1B). The size of exosomes abundantly ranged from 40 to $190 \mathrm{~nm}$ (Ave. Mean Size:70 $\pm 20 \mathrm{~nm}$, Fig. 1C). Under scanning electron microscopy (SEM), the purified exosomes exhibited a typical round-shaped structures (Fig. 1D). Collectively, these findings support that extracellular nanovesicles derived from $4 \mathrm{~T} 1 /$ Her2 cell line displays convincing exosome features. 
A.

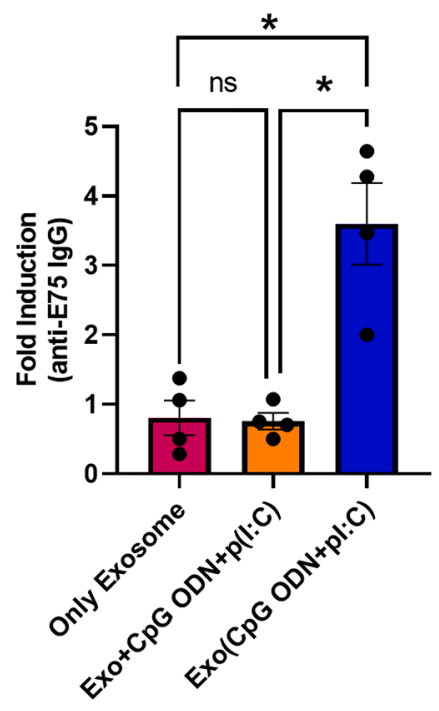

A.

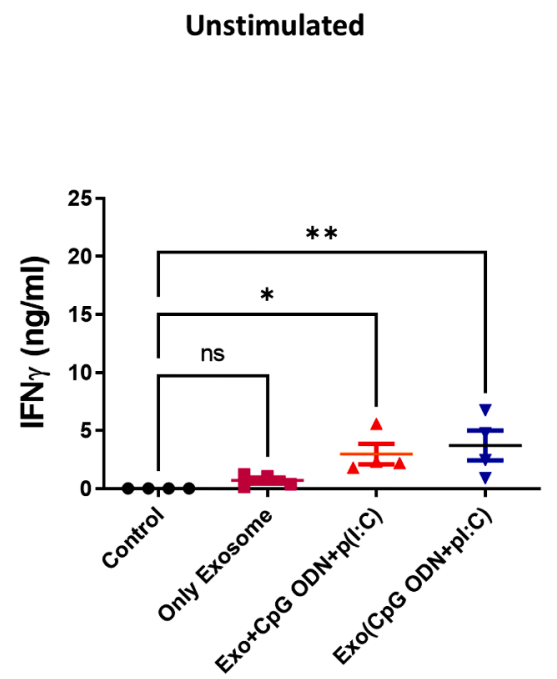

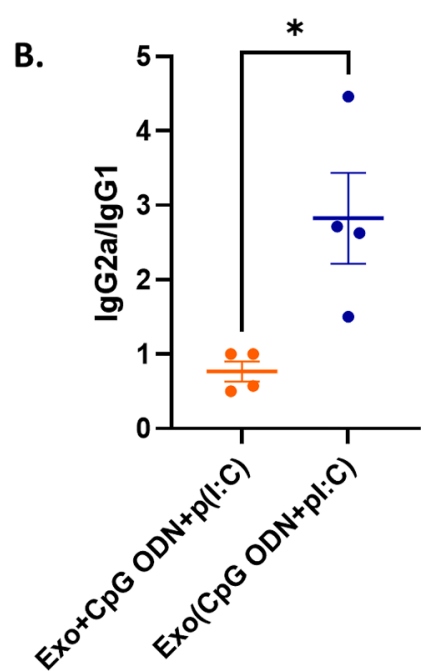

Fig. 3. 4T1/Her2 cell-derived exosome loaded with CpG ODN and $p(I: C)$ immunization magnified anti-E75 immune responses. Mice ( $n=4$ mice/group) were injected i.p. with PBS, only $30 \mu \mathrm{g}$ exosome, free form of $30 \mu \mathrm{g}$ exosome $+30 \mu \mathrm{g}$ CpG ODN and $30 \mu \mathrm{g}$ p(I:C) or exo(CpG ODN $+p(\mathrm{I}: \mathrm{C}))$ on days 0 and 14 . Mice were sacrificed on 14 day after the booster injection A) Bar graphs showing fold induction over control group of sera of immunized mice for systemic antibody production against Her2/E75 peptide. B) IgG2a/IgG1 ratio of individual mouse either immunized with free or immunized with EV formulation at 2 weeks after booster injection (at 1:30 dilution against Her2/E75 peptide). MannWhitney test was used for statistical analysis. The data indicate the mean \pm SEM $(n=4)$. Statistically significant differences designated as follows: ns: $p>0.05$, * $p<0.05$. Exo: exosome.
B.

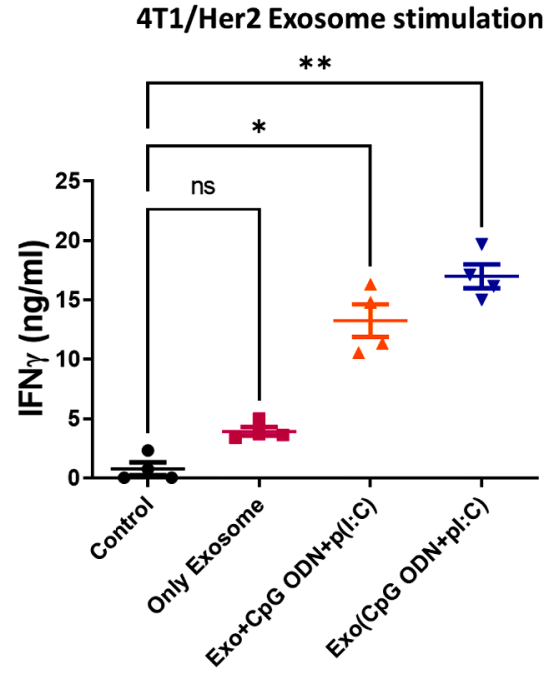

Fig. 4. IFN $\gamma$ assay on ex vivo expanded splenocytes of mice immunized two times with PBS, unencapsulated $30 \mu \mathrm{g}$ exosome, mixture of $30 \mu \mathrm{g}$ Exosome $+30 \mu \mathrm{g}$ CpG ODN and $30 \mu \mathrm{g}$ (I:C) or exosome coloaded with (CpG ODN $+p(\mathrm{I}: \mathrm{C})$ ) A) Fourteen days after the booster, the spleens of mice from each group were harvested and immune responses were evaluated using an IFN $\gamma$ ELISA assay. B) Fourteen days after the booster, spleens of mice $(n=4)$ were harvested and incubated with 4T1/Her2 exosome in culture for $72 \mathrm{hrs}$ and the secreted IFN $\gamma$ levels were then evaluated using IFN $\gamma$ ELISA kit. The data indicate the mean \pm SEM $(n=$ 4). Statistical significance was analyzed by Kruskal Wallis test. Statistically significant differences designated as follows: ns: $p>0.05,{ }^{*}: p<0.05,{ }^{* *}: p<0.01$. Exo:exosome.

\subsection{Humoral immune responses}

We intended to develop an exosomal carrier system co-encapsulating two nucleic acid-based TLR ligands as immunoadjuvants naturally expressing tumor-associated antigen Her2 and analyzed its potency as a prophylactic and therapeutic vaccine. Previous studies have shown that tumor derived exosomes have a dual effect on the immune system, immunosuppressive or immunostimulatory effects. To combine and enhance the synergistic immunostimulatory activity of TLR3 (p(I:C)) and TLR9 (CpG ODN) ligands, we co-encapsulated them within 4T1/ Her2 cell-derived exosomes thereby aimed to achieve simultaneous antigen and adjuvant delivery to relevant antigen presenting cell. Next, we assessed the humoral responses from sera of mice collected at day 28 following twice (@Day =0 and 14) i.p. injection to Balb/c mice. 4T1/ Her2-specific total IgG, IgG1 and IgG2a titers against 4T1/Her2 total cellular protein extract or $4 \mathrm{~T} 1 / \mathrm{Her} 2$ total exosome extract were analyzed by ELISA. As expected, there was no 4T1/Her2-specific antibody production in the control group and only exosome injected animals raised strong antibody titers. Besides, the level of $4 \mathrm{~T} 1 / \mathrm{Her} 2$ specific total IgG, IgG1 and IgG2a in sera of mice immunized with dual ligandloaded exosomal group was significantly higher than those animals that was immunized with free combination of antigen containing exosome and TLR ligands (Fig. 2A-C and Fig 2E-G). We also detected significantly elevated IgG2a/IgG1 ratio after immunization with exosomes co-encapsulating $\mathrm{p}(\mathrm{I}: \mathrm{C})$ and $\mathrm{CpG}$ ODN indicating the development of antigen specific Th1-biased immunity ( $p=0.0286$ for both antigens) (Fig. 2D and Fig 2H).

Furthermore, we analyzed whether exosome loaded with CpG ODN and $\mathrm{p}(\mathrm{I}: \mathrm{C})$ produce Her2 specific antibodies. To assess this, we used Her2 specific E75 peptide. As shown in Fig. 3A, mice immunized with dual ligand loaded exosomes produced significantly higher Her2/E75 specific total IgG antibody compared to mice immunized with only exosome and free form of exosomal combination $(p=0.0286)$. We detected significantly elevated IgG2a/IgG1 ratio after immunization with CpG ODN plus $\mathrm{p}(\mathrm{I}: \mathrm{C}$ ) loaded exosomes ( $p=0.0286$ for both antigens, Fig. 3B). Collectively these results pointed out that CpG ODN and p(I:C) loaded exosomes elicited anti-4T1/Her2 and Her2/E75 specific Th1-biased immunity.

\subsection{Induction of specific IFN $\gamma$ from splenocytes}

To evaluate the type of immune response generated, splenocytes 
A.

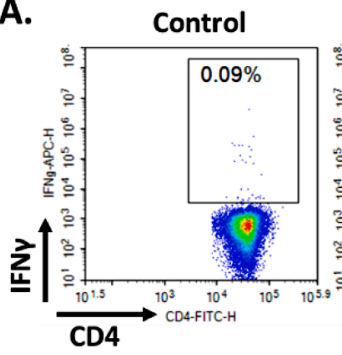

Only Exosome
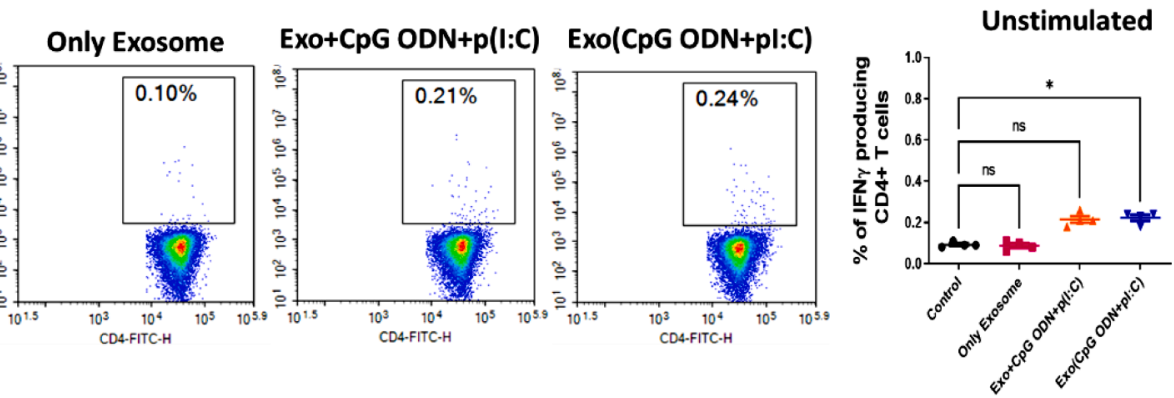

B.

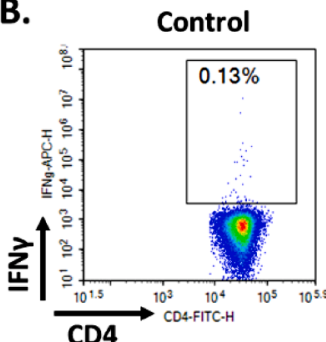

Only Exosome
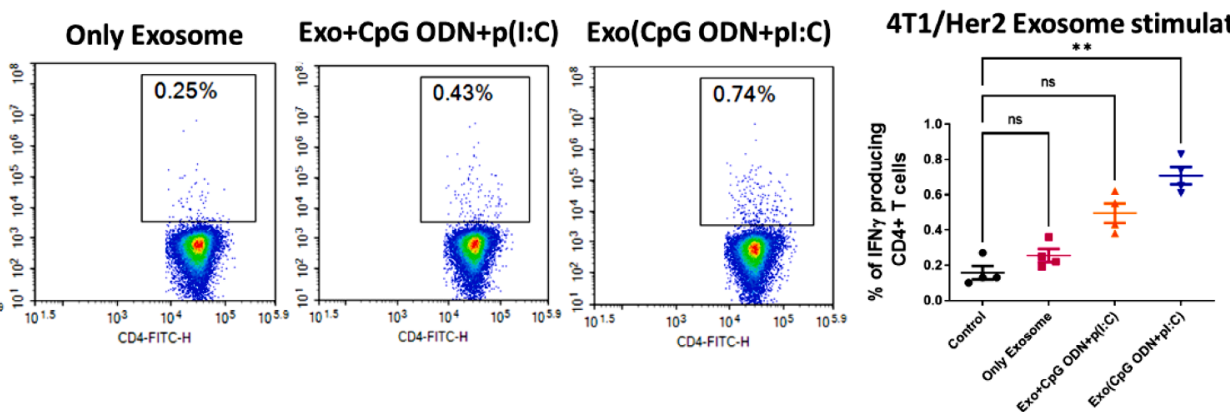

Fig. 5. Intracellular cytokine production from splenocytes of mice immunized two times with PBS, unencapsulated $30 \mu \mathrm{g}$ exosome, mixture of $30 \mu \mathrm{g}$ exosome plus $30 \mu \mathrm{g} \mathrm{CpG} \mathrm{ODN} \mathrm{and} 30 \mu \mathrm{g}$ p(I:C) or exosome co-loaded with (CpG ODN $+p(\mathrm{I}: \mathrm{C})$ ). A) Fourteen days after the booster, isolated splenocytes of different groups of vaccinated mice (4 mice from each group) were stained with CD45-PE/Cy7, CD3-Pacific Blue, CD4-FITC surface markers and then with anti-IFN $\gamma$ APC antibodies. B) Fourteen days later the booster, isolated splenocytes of different groups of vaccinated mice were stimulated with $4 \mathrm{~T} 1 / \mathrm{Her} 2$ exosome for 24 hrs in culture and stained with CD45-PE/Cy7, CD3-Pacific Blue, CD4-FITC surface markers and then with anti-IFN $\gamma$-APC antibodies. The frequency of IFN- $\gamma$ producing cells within CD4+ population were determined by Novocyte 3000 Cell analyzer. The data indicate the mean \pm SEM $(n=4)$. Statistical significance was analyzed by Kruskal Wallis test. Statistically significant differences designated as follows: ns: $p>0.05,{ }^{*}: p<0.05,{ }^{* *}: p<0.01$. Exo:exosome.

A.

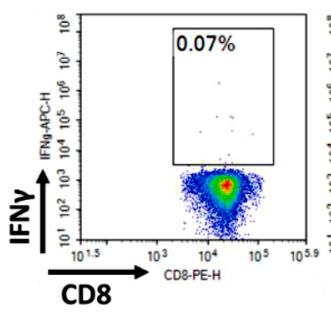

B.

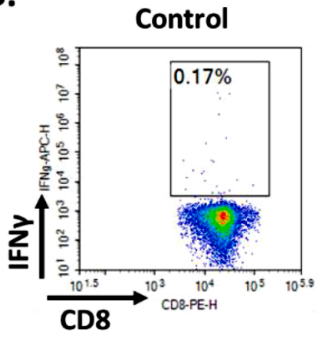

Only Exosome

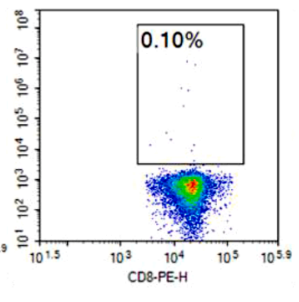

Only Exosome

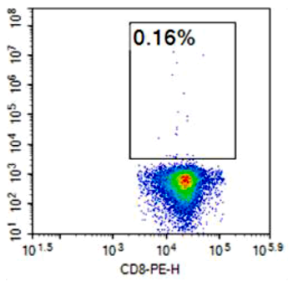

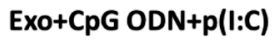

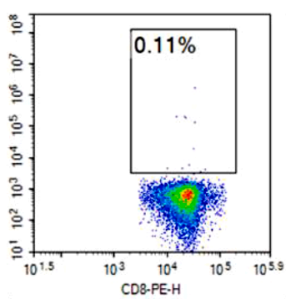

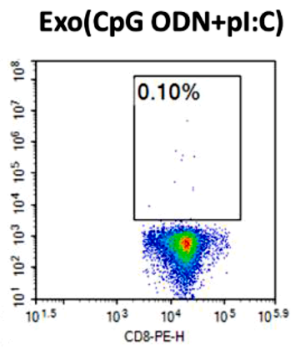

ExO+CpG ODN+p(I:C)
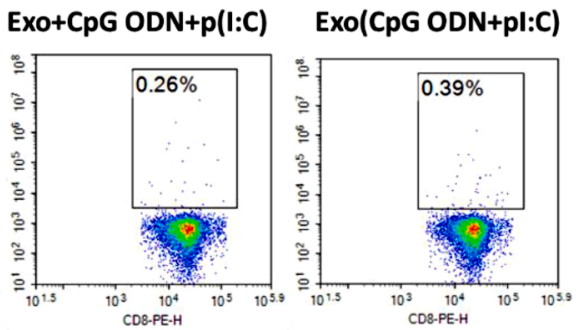

Unstimulated

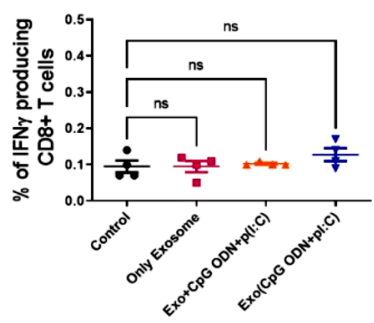

4T1/Her2 Exosome stimulation

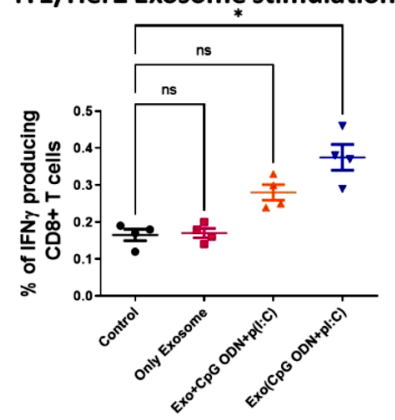

Fig. 6. Intracellular cytokine production assay on splenocytes of mice immunized two times with PBS, unencapsulated $30 \mu \mathrm{g}$ exosome, mixture of $30 \mu \mathrm{g}$ exosome $+30 \mu \mathrm{g} \mathrm{CpG}$ ODN and $30 \mu \mathrm{g}$ p(I:C) or exosome co-loaded with (CpG ODN+p(I:C)). A) Fourteen days later after the booster, isolated splenocytes of different groups of vaccinated mice (4 mice from each group) were stained with CD45-PE/Cy7, CD3-Pacific Blue, CD8-PE surface markers and then with anti-IFNyAPC antibodies. B) Fourteen days later after the booster, isolated splenocytes of different groups of vaccinated mice were incubated with 4T1/Her2 exosome for 24 hrs and stained with CD45-PE/Cy7, CD3-Pacific Blue, CD8-PE surface markers and then with anti-IFN $\gamma$-APC antibodies. The frequency of IFN- $\gamma$ producing cells within CD8+ population were determined by Novocyte 3000 Cell analyzer. The data indicate the mean \pm SEM $(n=4)$. Statistical significance was analyzed by Kruskal Wallis test. Statistically significant differences designated as follows: ns: $p>0.05,{ }^{*}: p<0.05$. Exo:exosome. 
A.

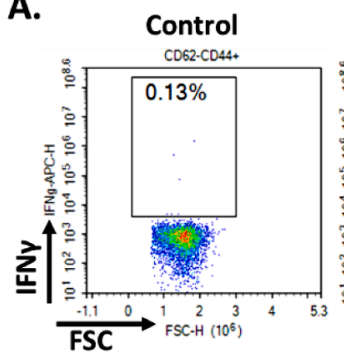

Only Exosome

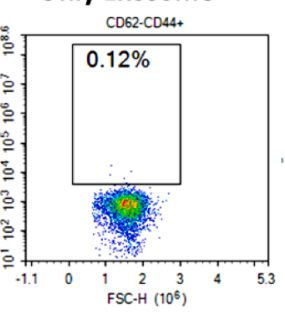

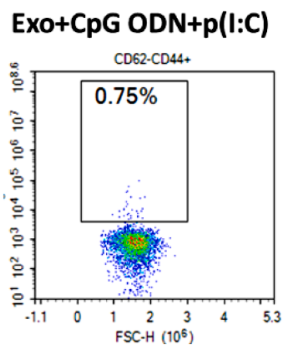

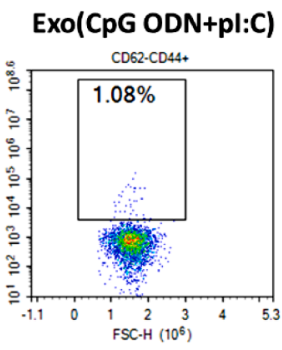

B.

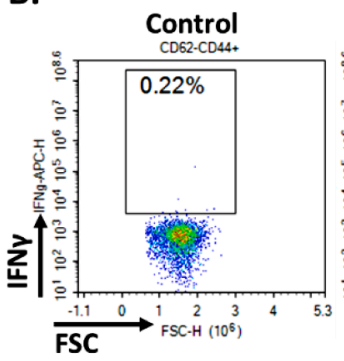

Only Exosome

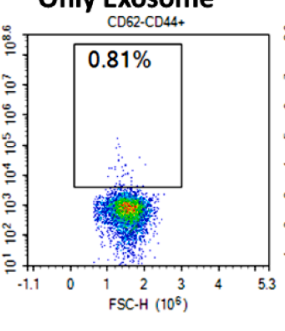

Exo+CpG ODN+p(l:C)

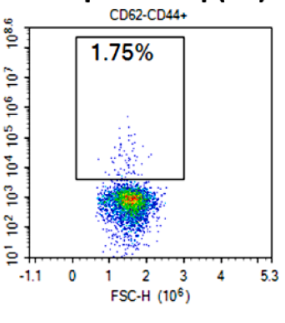

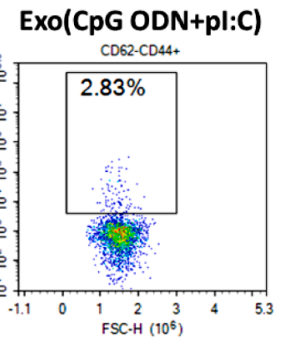

Unstimulated

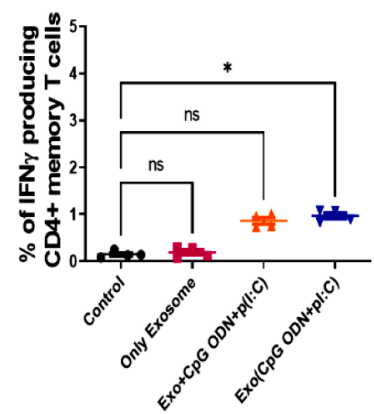

4T1/Her2 Exosome stimulation

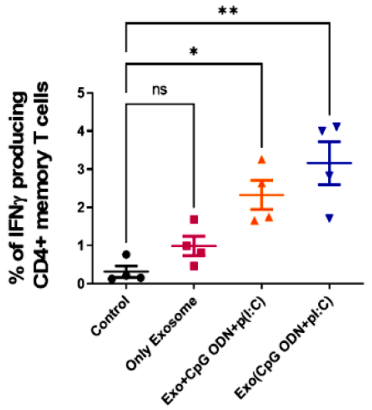

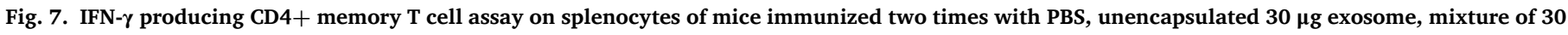

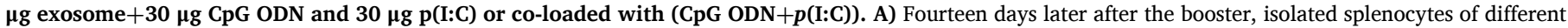

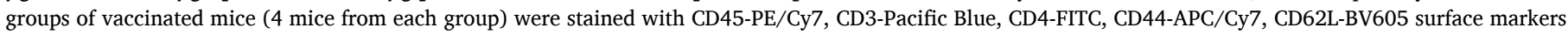

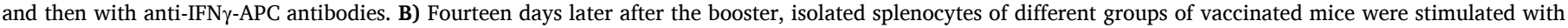

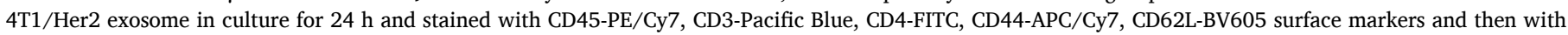

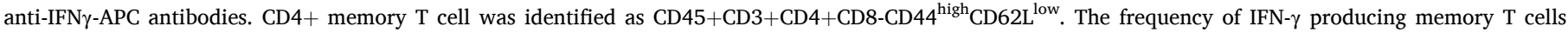

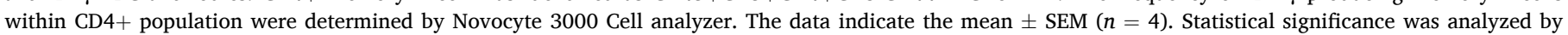
Kruskal Wallis test. Statistically significant differences designated as follows: ns: $p>0.05,{ }^{*}: p<0.05$, ${ }^{* *}: p<0.01$. Exo:exosome.

were isolated two weeks after the last booster injection and IFN $\gamma$ production was analyzed by ELISA assay. As shown in Fig. 4A, we detected that both non-encapsulated combination and dual ligand coencapsulated exosome group generated more IFN $\gamma$ compared to control group ( $p=0.0143, p=0.0089$, respectively). Furthermore, Fig. 4B shows that when the splenocytes of immunized mice were activated with 4T1/Her2 exosomes, specific IFN $\gamma$ productions of nonencapsulated combination and co-encapsulated exosome group were boosted significantly compared to control groups ( $p=0.0347, p=$ 0.0019 , respectively).

\section{4. $C D 4+$ and $C D 8+T$ cell responses}

To further differentiate the contribution of TLR ligand coencapsulation within exosomes on cellular immunity that was raised against 4T1 tumors, we performed IFN $\gamma$ specific intracellular cytokine staining on splenocytes. To this end, the IFN $\gamma+T$-cell subsets following staining of CD4 and CD8 positive T cells were analyzed by flow cytometry. The data showed that before and after 4T1/Her2 exosome stimulation in culture the induction of IFN $\gamma$ producing $+\mathrm{CD} 4 \mathrm{~T}$ cells were significantly higher in mice immunized with exosomes loaded with TLR ligands compared to the control groups. $(P=0.046, P=0.0032$ respectively) (Fig. 5A, B).

As seen in Fig 6, similarly intracellular cytokine staining assay revealed that when splenocytes were stimulated overnight with 4T1/ Her2 exosome in culture, only Exo(CpG ODN+p(I:C)) group had significantly augmented IFN $\gamma$ production from CD8 $+T$-cells compared to the control group ( $P=0.0127)$.

$4 \mathrm{~T} 1 /$ Her2 specific memory T-cell is one of the major contributing cell populations to eliminate Her2 expressing tumor cells, therefore, we analyzed the immunized mice splenocytes to assess the antigen-specific CD4+ memory $\mathrm{T}$ cell percentage. We determined that mice immunized with $\operatorname{Exo}(\mathrm{CpG}$ ODN $+\mathrm{p}(\mathrm{I}: \mathrm{C}))$ generated significantly higher IFN $\gamma$ producing CD4+ memory T cell compared to the control group $(p=0.016)$ (Fig. 7A). When immunized mice cells were incubated with 4T1/Her2 expressing exosome, IFN $\gamma$ producing $\mathrm{CD} 4+$ memory $\mathrm{T}$ cells expanded significantly in Exo(CpG ODN $+p(\mathrm{I}: \mathrm{C}))$ treated group compared to the control group $(p=0.0042)$ (Fig. 7B).

\subsection{Therapeutic effects of exosome vaccination in 4T1-luc bearing $B A L B / c$ mice}

Considering the strong cellular and humoral immune responses in vaccinated mice (Figs. 2-7), it was expected that the immune responses would lead to antitumor activity in an established 4T1-luc tumor model. To evaluate if the cellular and humoral immune responses induced by the $\operatorname{Exo}(\mathrm{CpG} O \mathrm{ODN}+\mathrm{p}(\mathrm{I}: \mathrm{C}))$ vaccination were potent enough to induce an in vivo antitumor effect, the mice were injected with 4T1-luc tumor cells orthotopically into the right mammary fat pads. Following after tumor inoculation, animals were intraperitoneally injected with Exo(CpG $\mathrm{ODN}+p(\mathrm{I}: \mathrm{C}))$ and were observed for tumor regression during 36 days post tumor formation. As shown in Fig. 8A, during the days 10-36, the group of mice that received Exo(CpG ODN+p(I:C)) regressed tumor development significantly in comparison with untreated control group ( $P=0.0045$ for day 32 and $P=0.0024$ for day 36 ). Also, the survival time was significantly prolonged in Exo(CpG ODN + p(I:C)) treated groups in comparison with the control group receiving PBS $(P=$ 0.0229). All mice belonging to control group were dead by day 49 whereas 3 out of 5 mice treated with Exo(CpG ODN+p(I:C)) were alive by day 60 . Furthermore, We analyzed the IFN $\gamma$ secretion, helper $\mathrm{T}$ cell and cytotoxic $\mathrm{T}$ cell population from splenocytes of animals that treated with the PBS and CpG ODN+p(I:C) loaded exosomes at day $=1,4,7,10$, 17, 24 and 31 after tumor inoculation. As shown in Fig. 8B, Splenocytes from animals that treated with TLR ligands loaded formulation secretes 
A.
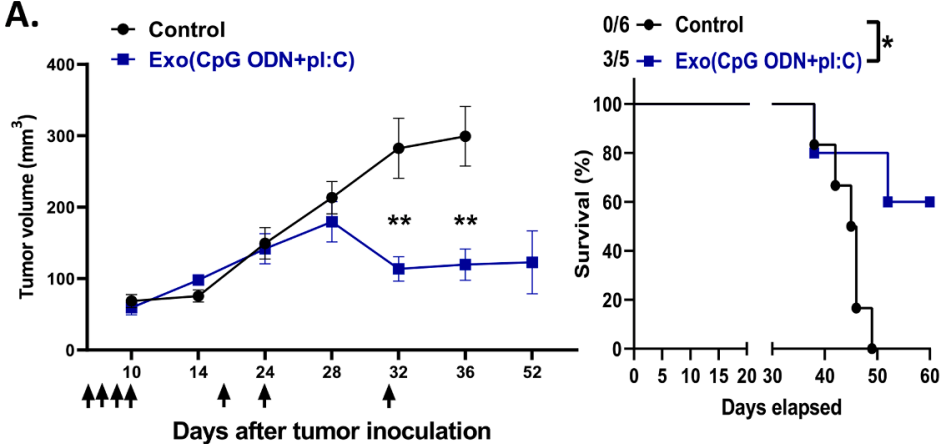

C.

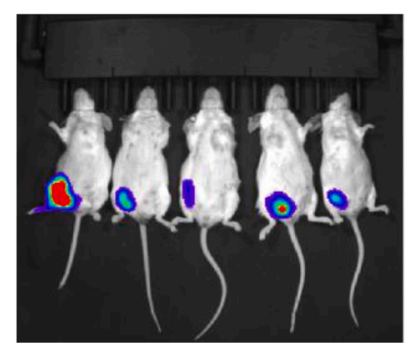

Exo(CpG ODN+pl:C)-day32

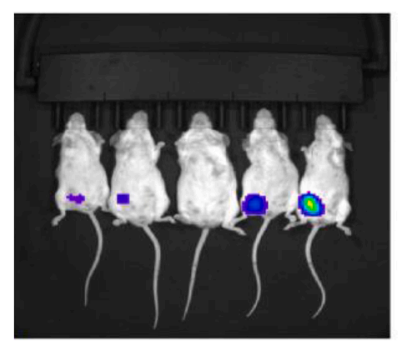

B.

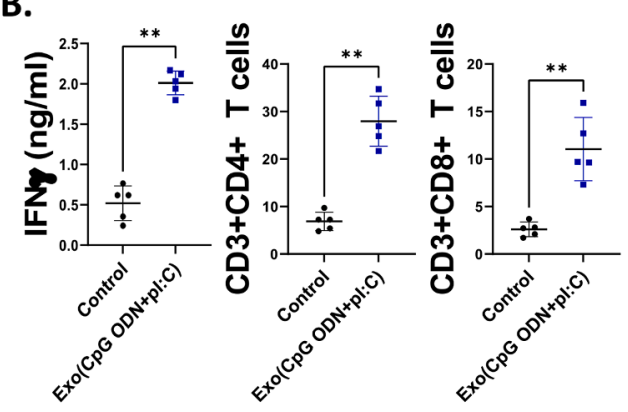

D.
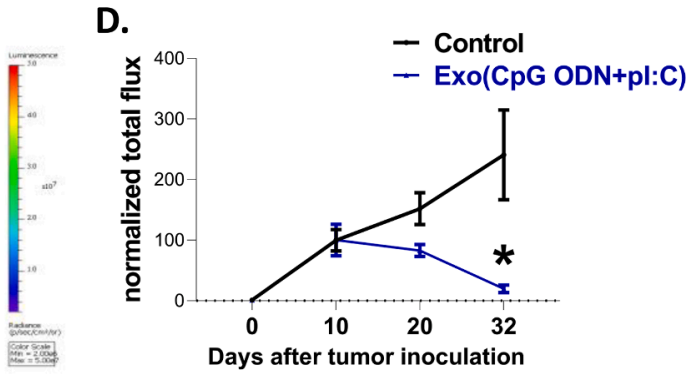

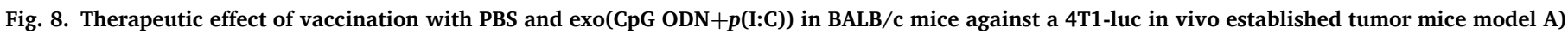

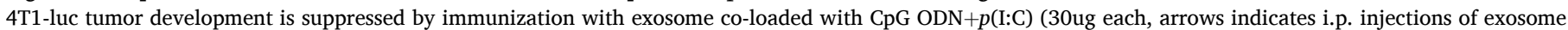

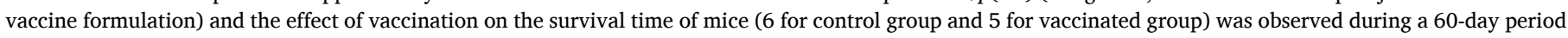

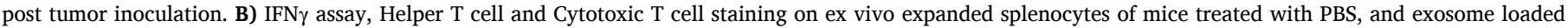

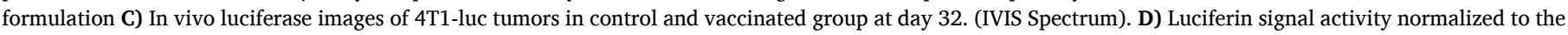

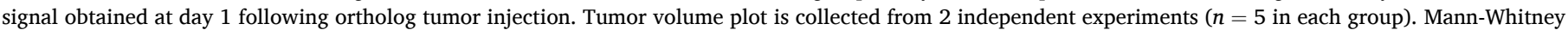

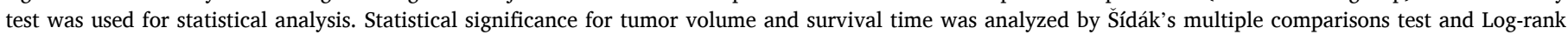

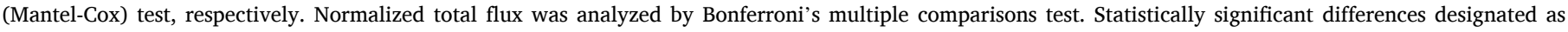
follows: ns: $p>0.05,{ }^{*}: p<0.05,{ }^{* *}: p<0.01$.Exo:exosome.

significantly higher level of IFN $\gamma$. Also, we found that the percentage of CD4+ and CD8+ T cells in splenocytes are significantly higher than mice treated with TLR ligands loaded exosomes compared to control group $(P$ $=0.0079)$. The anti-tumor effect of $\operatorname{Exo}(\mathrm{CpG} \mathrm{ODN}+p(\mathrm{I}: \mathrm{C}))$ group was evaluated by measurement using an IVIS imaging system. We measured bioluminescence activity every 10 days (day 0, day 10, day 20 and day 32 after tumor inoculation).As shown in the bioluminescence imaging results at day32, 1 out of 5 mice treated with Exo(CpG ODN+p(I:C)) had no luciferase signal (Fig. 8C) and exosome treated group had significantly lower luciferin activity over time (Fig. 8D)

Collectively, our findings implied that a combination of $\mathrm{p}(\mathrm{I}: \mathrm{C})$ and CpG ODN ligands within exosomal formulations induced stronger and persistent humoral and cellular anti-4T1/Her2 specific immune response sufficient to regress tumor growth.

\section{Discussion}

Tumor-derived exosomes (TEXs) are promising candidates as the next generation immuno-therapeutic vaccines against cancers. Besides being a good reservoir of various tumor antigens, TEXs take an active role in the communication of tumor cells in all steps of cancer development and regulate immune responses through both immunosuppressive and immunostimulatory functions [31]. It is of great significance to consider the safety profile of ligand loaded exosomes as less detrimental cancer antigen carriers as they initiate inflammatory responses due to its immunostimulatory nature of its cargo. We anticipate that the safety concerns could be alleviated due to its inflammatory character when harnessed as a therapeutic vaccine carrier. Due to this differential role of TEXs, and their limited immunogenicity, their modifications into an effective immuno-adjuvant delivery system that can stimulate a strong humoral and cell-mediated immune responses remains a challenge. In this study, we modified 4T1/Her2-cell-derived exosomes by loading with two potent adjuvants, CpG ODN and p(I:C). Modified exosomes co-encapsulating both $\mathrm{CpG}$ ODN and $\mathrm{p}(\mathrm{I}: \mathrm{C})$ have shown immunostimulatory properties by activating antigen-specific primary and memory $\mathrm{T}$ cell responses. Furthermore, our exosome-based adjuvant vaccine stimulated robust Th1 type immune responses via the elevated secretion of IgG2a antibody and IFN $\gamma$, resulting in tumor regression in 4T1 tumor-bearing mice.

Combination of TLR adjuvants like CpG ODN and $\mathrm{p}(\mathrm{I}: \mathrm{C})$ triggers synergistic immune response more apparently than their standalone counterparts when given within a carrier system [32]. Therefore, we evaluated to immunogenicity of modified TEXs co-encapsulated with the combination of both adjuvants. As expected, administration of only tumor derived exosomes to the mice did not generate statistically significant responses while exosomes loaded with CpG ODN and p(I:C) significantly increased $\mathrm{CD} 4+$ and $\mathrm{CD} 8+T$ cell responses and the production of antigen-specific antibodies (Fig. 2-7). It is important to note that while mixing exosomes with $\mathrm{CpG}$ ODN and $\mathrm{p}(\mathrm{I}: \mathrm{C})$ improves $\mathrm{CD} 4+$ and $\mathrm{CD} 8+T$ cell specific IFN $\gamma$ this response is neither significant from untreated control nor exosome alone treated animals. In this respect, only encapsulation of ligands within exosomes triggered significantly higher IFN $\gamma$ from the these animals, although comparison of mixture treated group vs ligand loaded exosome group animals did not yield significantly different responses. Since co-encapsulating CpG ODN and $\mathrm{p}$ (I:C) was the most active than other treatment groups, we investigated its potential therapeutic effect against the established 4T1 tumor model in mice. Our exosome-based adjuvant formulation significantly regressed tumor growth (Fig. 8). Furthermore, the simple co-administration of adjuvant with TEXs in clinical trials resulted in insufficient anti-tumor immunity due to inefficient simultaneous delivery of tumor antigen and adjuvant to the same antigen presenting cells (APCs) [33]. In the present study, we successfully encapsulated two adjuvants into TEXs carrying endogenous antigens and have shown that 
compared to co-administration mixture of (Exo+CpGODN+p(I:C)), co-encapsulation Exo(CpG ODN + p(I:C)) strategy yielded i) stronger antigen-specific Th1-biased humoral immunity, ii) higher levels of IFN $\gamma$ secretion and iii) more IFN $\gamma$ producing $\mathrm{CD} 4+$ and $\mathrm{CD} 8+\mathrm{T}$ cells (Fig. 2-6).

Induction of tumor antigen-specific cytotoxic $\mathrm{T}$ lymphocytes and humoral immune responses generated by efficient delivery of tumor antigens to APCs are essential requirements for effective cancer immunotherapy [34]. For this reason, vaccines against cancers focus on the identification of immunogenic antigen epitopes that selectively stimulates the induction of robust $\mathrm{T}$ helper cells, B cells and cytotoxic $\mathrm{T}$ cells [35]. However, only a few tumor-associated antigens have been identified for many cancer types and they can be poorly immunogenic or may not be found in a significant percentage of patients [36]. Moreover, the identification and purification of new epitopes that can be able to activate $\mathrm{T}$ and $\mathrm{B}$ cells are incredibly challenging. Using experimental approaches to screen immunodominant epitopes is quite expensive and its complexity is required the support of bioinformatic based predictions. Therefore, we proposed to harness tumor-derived exosomes isolated from the tumor biopsy or a tumor cell that are capable of expressing all biologically relevant antigens (including the neoantigens) as an efficient cancer vaccine carrier, thereby excludes the need to identify these epitopes. Her2 is considered as an ideal target for cancer vaccine development regarding its 100 -fold higher overexpression in patients with breast cancer and correlates with poor clinical outcomes [37]. E75 is a 9-amino acid human leukocyte antigen- (HLA-) restricted peptide located in the Her2 extracellular domain, which is currently under clinical trials [38]. Studies have shown that E75 peptide vaccine improve CTL and CD4+ Th1 responses [39,40], however, this vaccine can be used in limited patient population due to HLA class I restriction. Using TEXs from HER2-overexpressing cell lines as an adjuvant delivery system overcomes this restriction and activate more broad immune responses, since these exosomes express a full length Her2 molecule (Fig. 1) as well as the whole panel of tumor related antigens. Therefore, TEXs are potent delivery systems that can stimulate a breadth of $\mathrm{T}$ cell clones by presenting multiple antigenic epitopes. Besides stimulating strong Th1 type immune responses via the elevated production of IgG2a antibody against 4T1/Her2-derived exosomes (Fig. 2), our 4T1/Her2-derived exosome-adjuvant formulation efficiently activated humoral immune responses against E75 peptide as well (Fig.3). Based on these findings, using tumor-derived exosomes as a delivery system for cancer immunotherapy is more convenient and suitable approach, as it is applicable to all cancer types, where biopsies are available from the patient.

In conclusion, we demonstrated that modified TEXs with CpG ODN and $\mathrm{p}(\mathrm{I}: \mathrm{C})$ co-encapsulation generated humoral and cell-mediated immune responses and regress tumor growth in 4T1 tumor-bearing mice. as a well as extended survival (Fig. 8). The combination of adjuvants with tumor antigens inherently expressed by tumor-derived exosomes (without inserting additional antigen epitope) exerted stronger antitumor immune responses. These findings propose a useful TEX-based adjuvant delivery system as a promising cell-free vaccine and are of great interest for future vaccine design experiments in the clinical practice.

\section{Funding}

This work was supported by Ministry of Development (Grant name: UMRAM-ASI, Project \#: 2015BSV302 to I.G.).

\section{Declaration of competing interest}

The authors confirm that there are no known conflicts of interest associated with this publication.

\section{Acknowledgments}

We thank Dr. Gamze Aykut for breeding and daily caring of our animals. We extend our appreciation to Prof. Dr. Mayda Gursel and Dr. Tamer Kahraman for their insightful comments and critical reading of the manuscript.

\section{References}

[1] A.D. Waldman, J.M. Fritz, M.J. Lenardo, A guide to cancer immunotherapy: from T cell basic science to clinical practice, Nat. Rev. Immunol. (2020) 20, https://doi. org/10.1038/s41577-020-0306-5.

[2] S. Stevanovic, Identification of tumour-associated T-cell epitopes for vaccine development, Nat. Rev. Cancer. 2 (2002), https://doi.org/10.1038/nrc841.

[3] T. Cancer, G. Atlas, Integrated genomic analyses of ovarian carcinoma the cancer genome atlas research network, Nature (2011) 474, https://doi.org/10.1038/ nature10166.Integrated.

[4] R.S. Riley, C.H. June, R. Langer, M.J. Mitchell, Delivery technologies for cancer immunotherapy, Nat. Rev. Drug Discov. 18 (2019), https://doi.org/10.1038/ s41573-018-0006-z.

[5] L. Zhou, P. Zhang, H. Wang, D. Wang, Y. Li, Smart nanosized drug delivery systems inducing immunogenic cell death for combination with cancer immunotherapy, Acc. Chem. Res. (2020) 53, https://doi.org/10.1021/acs.accounts.0c00254.

[6] M. Tkach, C. Théry, Communication by Extracellular Vesicles: where we are and where we need to go, Cell 164 (2016), https://doi.org/10.1186/s12951-02000711-5, 10.1016/j.cell.2016.01.043.

[7] M. Colombo, G. Raposo, C. Théry, Biogenesis, secretion, and intercellular interactions of exosomes and other extracellular vesicles, Annu. Rev. Cell Dev. Biol. (2014) 30, https://doi.org/10.1146/annurev-cellbio-101512-122326.

[8] D. Ha, N. Yang, V. Nadithe, Exosomes as therapeutic drug carriers and delivery vehicles across biological membranes: current perspectives and future challenges, Acta Pharm. Sin. B. (2016) 6, https://doi.org/10.1016/j.apsb.2016.02.001.

[9] E.V. B.atrakova, M.S. Kim, Using exosomes, naturally-equipped nanocarriers, for drug delivery, J. Control. Release. (2015) 219, https://doi.org/10.1016/j. jconrel.2015.07.030.

[10] J.G. Van den Boorn, J. Daßler, C. Coch, M. Schlee, G. Hartmann, Exosomes as nucleic acid nanocarriers, Adv. Drug Deliv. Rev. (2013) 65, https://doi.org/ 10.1016/j.addr.2012.06.011.

[11] P. Vader, E.A. Mol, G. Pasterkamp, R.M. Schiffelers, Extracellular vesicles for drug delivery, Adv. Drug Deliv. Rev. (2016) 106, https://doi.org/10.1016/j. addr.2016.02.006.

[12] Y. Huang, K. Liu, Q. Li, Y. Yao, Y. Wang, Exosomes function in tumor immune microenvironment, Adv. Exp. Med. Biol. (2018), https://doi.org/10.1007/978-3319-74470-4_7.

[13] J. Wolfers, A. Lozier, G. Raposo, A. Regnault, C. Théry, C. Masurier, C. Flament, S. Pouzieux, F. Faure, T. Tursz, E. Angevin, S. Amigorena, L. Zitvogel, Tumorderived exosomes are a source of shared tumor rejection antigens for CTL crosspriming, Nat. Med. 7 (2001), https://doi.org/10.1038/85438.

[14] M. Jiang, W. Zhang, R. Zhang, P. Liu, Y. Ye, W. Yu, X. Guo, J. Yu, Cancer exosomederived miR-9 and miR-181a promote the development of early-stage MDSCs via interfering with SOCS3 and PIAS3 respectively in breast cancer, Oncogene (2020) 39, https://doi.org/10.1038/s41388-020-1322-4.

[15] L. Alvarez-Erviti, Y. Seow, H. Yin, C. Betts, S. Lakhal, M.J.A. Wood, Delivery of siRNA to the mouse brain by systemic injection of targeted exosomes, Nat. Biotechnol. (2011) 29, https://doi.org/10.1038/nbt.1807.

[16] J.M. Cooper, P.B.O. Wiklander, J.Z. Nordin, R. Al-Shawi, M.J. Wood, M. Vithlani, A.H.V. Schapira, J.P. Simons, S. El-Andaloussi, L. Alvarez-Erviti, Systemic exosomal siRNA delivery reduced alpha-synuclein aggregates in brains of transgenic mice, Mov. Disord. (2014) 29, https://doi.org/10.1002/mds.25978.

[17] S.I. Ohno, M. Takanashi, K. Sudo, S. Ueda, A. Ishikawa, N. Matsuyama, K. Fujita, T. Mizutani, T. Ohgi, T. Ochiya, N. Gotoh, M. Kuroda, Systemically injected exosomes targeted to EGFR deliver antitumor microrna to breast cancer cells, Mol. Ther. (2013) 21, https://doi.org/10.1038/mt.2012.180.

[18] A. Taghikhani, Z.M. Hassan, M. Ebrahimi, S.M. Moazzeni, microRNA modified tumor-derived exosomes as novel tools for maturation of dendritic cells, J. Cell. Physiol. (2019) 234, https://doi.org/10.1002/jcp.27626.

[19] L. Wang, X. Zhou, W. Zou, Y. Wu, J. Zhao, X. Chen, G.G. Zhou, Exosomes containing miRNAs targeting HER2 synthesis and engineered to adhere to HER2 on tumor cells surface exhibit enhanced antitumor activity, J. Nanobiotechnology. 18 (2020).

[20] Z. Xu, S. Zeng, Z. Gong, Y. Yan, Exosome-based immunotherapy: a promising approach for cancer treatment, Mol. Cancer. 19 (2020), https://doi.org/10.1186/ s12943-020-01278-3.

[21] C.J. Desmet, K.J. Ishii, Nucleic acid sensing at the interface between innate and adaptive immunity in vaccination, Nat. Rev. Immunol. (2012) 12, https://doi.org/ 10.1038/nri3247.

[22] S. Pandey, T. Kawai, S. Akira, Microbial sensing by toll-like receptors and intracellular nucleic acid sensors, Cold Spring Harb. Perspect. Biol. 7 (2015), https://doi.org/10.1101/cshperspect.a016246.

[23] D.M. Klinman, Immunotherapeutic uses of CpG oligodeoxynucleotides, Nat. Rev. Immunol. (2004) 4, https://doi.org/10.1038/nri1329.

[24] A.M. Krieg, CpG still rocks! Update on an accidental drug, Nucleic Acid Ther (2012) 22, https://doi.org/10.1089/nat.2012.0340. 
[25] D.M. Klinman, D. Currie, I. Gursel, D. Verthelyi, Use of CpG oligodeoxynucleotides as immune adjuvants, Immunol. Rev. (2004) 199, https://doi.org/10.1111/j.01052896.2004.00148.x.

[26] C.H. Ewel, W.J. Urba, W.C. Kopp, J.W. Smith, R.G. Steis, J.L. Rossio, D.L. Longo, M. Jane Jones, W. Gregory Alvord, C.M. Pinsky, J.M. Beveridge, K.L. McNitt, S. P. Creekmore, Polyinosinic-Polycytidylic Acid Complexed with Poly-L-lysine and Carboxymethylcellulose in Combination with Interleukin 2 in Patients with Cancer: clinical and Immunological Effects, Cancer Res 52 (1992).

[27] J.L. Lepe-Zuniga, J. Rotbein, J.U. Gutterman, Production of interferon- $\alpha$ induced by dsRNA in human peripheral blood mononuclear cell cultures: role of priming by dsRNA-induced interferons- $\gamma$ and - $\beta$, J. Interferon Res. 9 (1989) https://doi.org/ 10.1089/jir.1989.9.445.

[28] A.E. Gelman, J. Zhang, Y. Choi, L.A. Turka, Toll-like receptor ligands directly promote activated CD4 + T cell survival, J. Immunol. (2004) 172, https://doi.org/ 10.4049/jimmunol.172.10.6065.

[29] M.L. Salem, A.N. Kadima, D.J. Cole, W.E. Gillanders, Defining the antigen-specific T-cell response to vaccination and poly(I:C)/TLR3 signaling: evidence of enhanced primary and memory CD8 T-cell responses and antitumor immunity,

J. Immunother. 28 (2005), https://doi.org/10.1097/01.cji.0000156828.75196.0d.

[30] R. Perret, S.R. Sierro, N.K. Botelho, S. Corgnac, A. Donda, P. Romero, Adjuvants that improve the ratio of antigen-specific effector to regulatory $\mathrm{T}$ cells enhance tumor immunity, Cancer Res 73 (2013), https://doi.org/10.1158/0008-5472.CAN13-0875.

[31] W. Olejarz, A. Dominiak, A. Zołnierzak, G. Kubiak-Tomaszewska, T. Lorenc, Tumor-derived exosomes in immunosuppression and immunotherapy, J. Immunol. Res. (2020), https://doi.org/10.1155/2020/6272498.

[32] M. Krummen, S. Balkow, L. Shen, S. Heinz, C. Loquai, H.-.C. Probst, S. Grabbe, Release of IL-12 by dendritic cells activated by TLR ligation is dependent on MyD88 signaling, whereas TRIF signaling is indispensable for TLR synergy, J. Leukoc. Biol. (2010) 88, https://doi.org/10.1189/jlb.0408228.

[33] Y. Sun, J. Liu, Potential of cancer cell-derived exosomes in clinical application: a review of recent research advances, Clin. Ther. (2014) 36, https://doi.org/ 10.1016/j.clinthera.2014.04.018.

[34] A.W. P., J. M., J. R., More than one reason to rethink the use of peptides in vaccine design, Nat. Rev. Drug Discov. 6 (2007).
[35] J.S. Testa, R. Philip, Role of T-cell epitope-based vaccine in prophylactic and therapeutic applications, Future Virol 7 (2012), https://doi.org/10.2217/ fvl.12.108.

[36] A. Arora, S.A. Ahmad, C.E. Binkley, W.M. Burke, A.E. Chang, V.M. Cimmino, K. M. Diehl, G.M. Doherty, D.A. DuBay, E.M. Gartner, P.G. Gauger, J.D. Geiger, S. D. Gitlin, K. Graziano, P.J. Hodul, E.H. Huang, M.D. Iannettoni, K.M. Woods Ignatoski, C. Johnston, J. Kim, J. Lin, Q.P. Ly, E.A. Newman, J.M. Pow-Sang, M. E. Ray, A. Rodriguez, D.E. Rollison, M.S. Sabel, E.A. Shaughnessy, D.M. Simeone, V.K. Sondak, S.L. Sugg, J.J. Sussman, S. Tsai, C.Y. Williams-Covington, K. Wilson, M.J. Wolfe, D.T. Woodrum, Contributors, Essentials Surg. Oncol. (2007), https:// doi.org/10.1016/b978-0-8151-4385-7.50004-7.

[37] Y. Yarden, Biology of HER2 and its importance in breast cancer, Oncology (2001), https://doi.org/10.1159/000055396.

[38] R.L.B. Costa, B.J. Czerniecki, Clinical development of immunotherapies for HER2+ breast cancer: a review of HER2-directed monoclonal antibodies and beyond, Npj Breast Cancer 6 (2020), https://doi.org/10.1038/s41523-020-0153-3.

[39] E.A. Mittendorf, J.P. Holmes, S. Ponniah, G.E. Peoples, The E75 HER2/neu peptide vaccine, Cancer Immunol. Immunother (2008), https://doi.org/10.1007/s00262008-0540-3.

[40] M.T. Hueman, A. Stojadinovic, C.E. Storrer, Z.A. Dehqanzada, J.M. Gurney, C. D. Shriver, S. Ponniah, G.E. Peoples, Analysis of naive and memory CD4 and CD8 T cell populations in breast cancer patients receiving a HER2/neu peptide (E75) and GM-CSF vaccine, Cancer Immunol. Immunother. (2007) 56, https://doi.org/ 10.1007/s00262-006-0188-9.

[41] M.H. Kershaw, J.T. Jackson, N.M. Haynes, et al., Gene-engineered T cells as a superior adjuvant therapy for metastatic cancer, J. Immunol. 173 (3) (2004) 2143-2150.

[42] C.S. Özverel, Y. Uyanikgil, İ. Karaboz, A. Nalbantsoy, Investigation of the combination of anti-PDL1 mAb with HER2/neu-loaded dendritic cells and QS-21 saponin adjuvant: effect against HER2 positive breast cancer in mice, Immunopharmacol Immunotoxicol 42 (4) (2020) 346-357, https://doi.org/ 10.1080/08923973.2020.1775644.

[43] M.Fang K.Tao, G.G.Sahagian J.Alroy, Imagable 4T1 model for the study of late stage breast cancer, BMC Cancer 8 (2008) 228, https://doi.org/10.1186/14712407-8-228. 